Article

Subscriber access provided by King Abdullah University of Science and Technology Library

\title{
Establishing efficient cobalt based catalytic sites for oxygen evolution on a Ta3N5 photocatalyst
}

Ela Nurlaela, Samy Ould-Chikh, Isabelle Llorens, Jean-louis HAZEMANN, and Kazuhiro Takanabe

Chem. Mater., Just Accepted Manuscript • DOI: 10.1021/acs.chemmater.5b02139 • Publication Date (Web): 05 Aug 2015

Downloaded from http://pubs.acs.org on August 9, 2015

\section{Just Accepted}

"Just Accepted" manuscripts have been peer-reviewed and accepted for publication. They are posted online prior to technical editing, formatting for publication and author proofing. The American Chemical Society provides "Just Accepted" as a free service to the research community to expedite the dissemination of scientific material as soon as possible after acceptance. "Just Accepted" manuscripts appear in full in PDF format accompanied by an HTML abstract. "Just Accepted" manuscripts have been fully peer reviewed, but should not be considered the official version of record. They are accessible to all readers and citable by the Digital Object Identifier (DOI®). "Just Accepted" is an optional service offered to authors. Therefore, the "Just Accepted" Web site may not include all articles that will be published in the journal. After a manuscript is technically edited and formatted, it will be removed from the "Just Accepted" Web site and published as an ASAP article. Note that technical editing may introduce minor changes to the manuscript text and/or graphics which could affect content, and all legal disclaimers and ethical guidelines that apply to the journal pertain. ACS cannot be held responsible for errors or consequences arising from the use of information contained in these "Just Accepted" manuscripts. 


\section{Introduction}

Water splitting using powder photocatalyst systems has attracted significant interest for the production of renewable hydrogen generation using abundant solar energy because of its simplicity, scalability, and low capital cost. ${ }^{1,2}$ To effectively convert solar energy, substantial utilization of photon energy in the visible-light range is essential. Using the AM $1.5 \mathrm{G}$ standard spectrum ${ }^{3}$, a photocatalyst with absorption from UV to $600 \mathrm{~nm}$ with a quantum efficiency of $30 \%$ accounts for $\sim 5 \%$ solar to hydrogen efficiency, making the technology commercially feasible. ${ }^{1,4}$ Among the photocatalysts investigated to date, tantalum $(\mathrm{V})$ nitride $\left(\mathrm{Ta}_{3} \mathrm{~N}_{5}\right)$ has emerged as one of the most promising candidates and has been extensively investigated for more than a decade. ${ }^{4-15} \mathrm{Ta}_{3} \mathrm{~N}_{5}$ has a visible-light response (approximately $600 \mathrm{~nm}, \sim 2.1 \mathrm{-eV}$ band gap) and is capable of producing hydrogen or oxygen in the presence of appropriate sacrificial reagents and surface modifications under visible-light irradiation. ${ }^{1,5-16}$ Our recent work on $\mathrm{Ta}_{3} \mathrm{~N}_{5}$ thin films for the photoelectrochemical oxygen evolution reaction (OER) noted that despite having suitable absorption in the visible-light range, $\mathrm{Ta}_{3} \mathrm{~N}_{5}$ suffered from very low transport properties and fast carrier recombination $(<10 \mathrm{ps})$ without any surface decoration. ${ }^{17}$ These detrimental intrinsic semiconducting properties might explain why overall water splitting has not been achieved at a detectable efficiency using $\mathrm{Ta}_{3} \mathrm{~N}_{5}$ as the main photocatalyst to date.
The efficiency of water splitting in a powder photocatalytic system is particularly affected by several factors associated with the photocatalyst and cocatalyst properties. Indeed, changes in the structural, electronic, optical, and morphological properties of the $\mathrm{Ta}_{3} \mathrm{~N}_{5}$ have been observed to have beneficial effects for improving its photocatalytic activity. ${ }^{15-23}$ Among these studies, our recent work reported that not only the bulk properties but also the surface properties greatly affected the photocatalytic activity of $\mathrm{Ta}_{3} \mathrm{~N}_{5}{ }^{24} \mathrm{~A}$ thin TaN layer on the surface $(\sim 2 \mathrm{~nm})$, which formed depending on the synthesis method, was observed to change the energetic profile on the $\mathrm{Ta}_{3} \mathrm{~N}_{5}$-electrolyte interface, thus changing the photocatalytic activity. ${ }^{24}$ Hence, despite the kinetic hindrance governed by the intrinsic properties, research design involving perturbing the surface properties of $\mathrm{Ta}_{3} \mathrm{~N}_{5}$ is believed to further improve its photocatalytic activity. ${ }^{24}$

Decreasing the bandgap of a photocatalyst will increase the number of potentially absorbable photons but, in turn, reduce the driving force for charge separation and the rate of subsequent redox reactions on the surface. ${ }^{25-26}$ An upward band bending (in the case of an n-type semiconductor) promotes easier hole transfer to the surface and subsequently initiates the OER on the surface. ${ }^{27-28}$ However, for a visible-lightresponsive photocatalyst, shifting the valence band to a more negative energy level results in the drawback of reducing the activity toward OER. Therefore, considerable efforts have 
been made to improve the OER by introducing an active electrocatalyst. $^{23,25,29-32}$

Cobalt oxide $\left(\mathrm{CoO}_{\mathrm{x}}\right)$ has been extensively investigated as a cocatalyst, particularly for electrochemical and photoelectrochemical OER. ${ }^{25,29-32,34,35}$ Although many studies have reported improvement of the electrochemical OER using $\mathrm{CoO}_{x}$, studies on powder suspension systems are limited. To date, quantum efficiencies as high as $27 \%$ (at $440 \mathrm{~nm}$ ) have been reported on $\mathrm{CoO}_{\mathrm{x}} / \mathrm{LaTiO}_{2} \mathrm{~N}$ for the OER in the presence of $\mathrm{Ag}^{+}$as a sacrificial reagent. ${ }^{25}$ Thus, $\mathrm{CoO}_{\mathrm{x}}$ is believed to play a vital role in providing active sites for the OER as well as in promoting charge separation. ${ }^{1,24,33}$ However, the exact role of the cobalt species (i.e., Co-Pi and $\mathrm{CoO}_{\mathrm{x}}$ ) on the photoanode material has been a matter of debate. ${ }^{33-36}$ Unlike in the electrochemical OER, when cobalt is added to the semiconductor surface, a new interface is created between the photoanode and cobalt cocatalyst. Hence, new band bending is introduced, thus promoting effective charge separation. ${ }^{36-39}$ The cobalt layer modifies not only the rate of electron transfer to and from the solution but also the equilibrium and non-equilibrium interface energetics. Furthermore, considering that $\mathrm{CoO}$ or $\mathrm{Co}_{3} \mathrm{O}_{4}$ are ptype semiconductors, some evidence has also led to the conclusion that a type of $p-n$ junction was created between the semiconductor and cobalt catalyst. ${ }^{40-41}$ Nevertheless, despite these differences, the information provided by the electrochemical OER can be rationalized to construct an effective OER system for a photoelectrochemical or photocatalytic system.

Despite tremendous effort on the development of a $\mathrm{CoO}_{x}$ catalyst, its chemical state and properties on a photocatalyst have yet to be elucidated. To examine the exact role and design an effective photocatalyst-electrocatalyst interface, systematic characterization is required. On the reported $\mathrm{La}_{2} \mathrm{Ti}_{2} \mathrm{ON}$ powder system, $\mathrm{CoO}_{\mathrm{x}}$ was synthesized by applying the wetimpregnation method followed by $\mathrm{NH}_{3}$ treatment at high temperature and post-oxidation. $\mathrm{CoO}_{\mathrm{x}}$ was identified as a mixed oxide of cobalt based on XPS and HRTEM. ${ }^{25}$ It is well known that under high temperature, $\mathrm{NH}_{3}$ decomposes into active nitriding species, such as $\mathrm{N}, \mathrm{NH}$, or $\mathrm{NH}_{2}$ ions and $\mathrm{H}_{2}$ gas, which may act as reducing agents for the cobalt species. ${ }^{42-43}$ Hence, there is the possibility that Co will be reduced or nitrogen will be inserted into the $\mathrm{CoO}_{x}$ species, forming a cobalt nitride phase. On a $\mathrm{Ta}_{3} \mathrm{~N}_{5}$ film for photoelectrochemical water splitting, Co has been deposited by dip coating and subjected to heat treatment under $\mathrm{NH}_{3}$ flow. Based on glancing incidence $\mathrm{X}$-ray diffraction (GIXRD), the main phases were identified to be orthorhombic-phase $\mathrm{Ta}_{3} \mathrm{~N}_{5}$ and cubic-phase $\mathrm{Co}_{5.47} \mathrm{~N}^{30}$ Although the cobalt precursors were introduced on top of the $\mathrm{Ta}_{3} \mathrm{~N}_{5}$ precursor (i.e., $\mathrm{TaCl}_{5}$ ) before nitridation, no $\mathrm{Ta}_{\mathrm{y}} \mathrm{Co}_{1-\mathrm{y}} \mathrm{N}_{\mathrm{x}}$ phase was detected.

The present study attempts to provide a detailed characterization of the cocatalyst modification of $\mathrm{Ta}_{3} \mathrm{~N}_{5}$ photocatalyst particulates. A cobalt species as an OER catalyst was immobilized via ammonia treatment, which produced reduced metallic cobalt as a contact at the semiconductor surface. This treatment was observed to be effective in improving the photocatalytic performance, although the catalyst was re-oxidized after the reaction.

\section{Experimental}

2.1. Photocatalyst synthesis
$\mathrm{Ta}_{3} \mathrm{~N}_{5}$ particles were prepared from as-purchased commercially available crystalline $\mathrm{Ta}_{2} \mathrm{O}_{5}(\geq 99.99 \%$ metal basis, $<5$ microns, Sigma-Aldrich) by applying direct $\mathrm{NH}_{3}$ nitridation under high temperature, as reported elsewhere. ${ }^{24,44}$ In a typical experiment, a total of $0.5 \mathrm{~g} \mathrm{Ta}_{2} \mathrm{O}_{5}$ was wrapped with quartz wool and placed into a tube furnace (ID $26 \mathrm{~mm}$ ) to provide homogeneous nitirided product. The tube furnace was initially purged with $\mathrm{N}_{2}$ before the introduction of $\mathrm{NH}_{3}$ flow at room temperature. The nitridation was conducted at $900{ }^{\circ} \mathrm{C}$ with a heating rate of $5{ }^{\circ} \mathrm{C} \mathrm{min}{ }^{-1}$ and was held at this temperature for $15 \mathrm{~h}$ under a $\mathrm{NH}_{3}$ flow of $200 \mathrm{~mL} \mathrm{~min}^{-1}$. The sample was allowed to cool to room temperature inside a tube furnace under $\mathrm{NH}_{3}$ flow.

Cobalt deposition onto the $\mathrm{Ta}_{3} \mathrm{~N}_{5}$ was conducted using the wet-impregnation method. ${ }^{18,25}$ In a typical experiment, a required amount of $\mathrm{Co}\left(\mathrm{NO}_{3}\right)_{2} \cdot 6 \mathrm{H}_{2} \mathrm{O}$ (Aldrich, 99\%) and $0.1 \mathrm{~g}$ $\mathrm{Ta}_{3} \mathrm{~N}_{5}$ were suspended in $5 \mathrm{~mL} \mathrm{H}_{2} \mathrm{O}$ and sonicated for $5 \mathrm{~min}$. The suspension was then subjected to evaporation to remove water under a slight vacuum at $70 \mathrm{mbar}$ for $30 \mathrm{~min}$ followed by $50 \mathrm{mbar}$ at $45^{\circ} \mathrm{C}$ for $30 \mathrm{~min}$. Subsequently, the resulting powder was subjected to heat treatment at various temperatures $\left(300,500,700\right.$, and $\left.900{ }^{\circ} \mathrm{C}\right)$ for $1 \mathrm{~h}$ under $200 \mathrm{~mL} \mathrm{~min}^{-1}$ $\mathrm{NH}_{3}$ flow. In a similar manner, the cooling process inside the tubular furnace was conducted under $\mathrm{NH}_{3}$ flow.

\subsection{Characterization}

XRD patterns were collected on a Bruker D8 Advance A25 diffractometer in the Bragg-Brentano geometry equipped with a $\mathrm{Cu}$ tube $\left(\mathrm{Cu}-\mathrm{K}_{\alpha} ; \lambda=0.15418 \mathrm{~nm}\right)$ operating at $40 \mathrm{kV}$ and $40 \mathrm{~mA}$ using a linear position-sensitive detector (opening $2.9^{\circ}$ ). The diffractometer was configured with a $0.44^{\circ}$ diverging slit, a $2.9^{\circ}$ antiscattering slit, $2.5^{\circ}$ Soller slits, and a nickel filter to attenuate the contributions from $\mathrm{Cu}-\mathrm{K}_{\beta}$ fluorescence. Data sets were acquired in continuous scanning mode over the $2 \theta$ range of $10-80^{\circ}$.

Raman spectra were obtained using a Horiba Aramis equipped with three laser sources: a He-Ne laser $(\lambda=632.8$ $\mathrm{nm})$, solid-state lasers ( $\lambda=532$ and $473 \mathrm{~nm})$, and a Peltiercooled CCD Andor iDus 420. All the spectra were acquired using $632.8 \mathrm{~nm}$ as the excitation wavelength in the $\mathrm{z}(\mathrm{x}, \mathrm{x})-\mathrm{z}$ backscattering geometry. To minimize the thermal effect and photodegradation of the sample, a limited laser power was selected. A resolution of $0.5 \mathrm{~cm}^{-1}$ in the range between 100 and $1000 \mathrm{~cm}^{-1}$ was selected. Repeated acquisitions using the highest magnification were accumulated to improve the signal-to-noise ratio. Spectra were calibrated using the 520.5 $\mathrm{cm}^{-1}$ line of a silicon wafer.

X-ray absorption spectroscopy (XAS) experiments were performed on the CRG-FAME beamline (BM30B) at the European Synchrotron Radiation Facility in Grenoble. Spectra were recorded either in fluorescence (photocatalysts) or transmission (reference) modes at the Co K-edge (7.709 keV). XAS data were analyzed using the HORAE package, a graphical interface to the AUTOBK and IFEFFIT code. ${ }^{45}$ XANES and EXAFS spectra were obtained after performing standard procedures for pre-edge subtraction, normalization, polynomial removal, and wavevector conversion. The amplitude factor $\left(\mathrm{S}_{0}{ }^{2}\right)$ was fitted to the EXAFS spectrum obtained for a cobalt metallic foil, the crystallographic structure being hexagonal $\left(\mathrm{P}_{3} / \mathrm{mmc}\right) . \mathrm{S}_{0}{ }^{2}$ was observed to be 0.80 . Quantitative XANES analyses were performed with the FDMNES code using the Multiple Scattering theory, where the Muffin-Tin approximation is made to describe the shape of the potential, ${ }^{46}$ quadrupo- 
lar transitions were included for the calculation of the theoretical absorption spectra.

Aberration-corrected high-angle annular dark-field scanning transmission electron microscopy (HAADF-STEM) was performed on a Titan G2 60-300 CT electron microscope at an accelerating voltage of $300 \mathrm{kV}$. The electron gun was used in the unfiltered mode, and the probe size during STEM analysis was estimated to be approximately $0.5 \mathrm{~nm}$ with a beam current of $0.08 \mathrm{nA}$. A large camera length of $360 \mathrm{~mm}$ was needed to observe $\mathrm{Ta}_{3} \mathrm{~N}_{5}$ and the cobalt-based cocatalyst together. Several low- and high-resolution electron micrographs were acquired from various locations during the analysis. Fast-Fourier transform (FFT) analysis was applied to various regions of the high-resolution STEM micrographs to investigate the crystal structure of the metallic cobalt nanoparticles. The elemental compositions of the samples were characterized based on the simultaneous acquisition of spectra from electron energy loss spectroscopy (EELS) and X-ray energy dispersive spectroscopy (EDX). The absorption K-edges of nitrogen and oxygen obtained by EELS and the fluorescence lines of cobalt $\left(\mathrm{K}_{\alpha 1, \alpha 2}\right)$ and tantalum $\left(\mathrm{L}_{\alpha 1, \alpha 2}\right)$ obtained by EDX were selected to build the chemical maps.

XPS studies were performed in an AMICUS/ESCA 3400 KRATOS using $\mathrm{Mg}$ anodes and a $\mathrm{K}_{\alpha}$-excitation X-ray source $(h v=1253.6 \mathrm{eV})$ operated at $10 \mathrm{kV}$ and $10 \mathrm{~mA}$. During the experiments, the pressure in the analysis chamber was maintained at $\sim 2 \times 10^{-6} \mathrm{~Pa}$. A prominent peak of $\mathrm{Ag} 3 \mathrm{~d}_{5 / 2}$ from the Ag substrate at $368.2 \mathrm{eV}$ was used to calibrate the spectra.

The amount of deposited Co in the samples was quantified by inductively coupled plasma-atomic emission spectrometry (ICP-AES) using a Thermo iCap 6500. Before analysis, $15 \mathrm{mg}$ of the sample was decomposed by an acid mixture of nitric acid and hydrochloric acid (under pressure and high temperature).

\subsection{Photocatalytic reaction}

The photocatalytic reactions were performed in a recirculating batch reactor connected to a gas chromatography (GC) unit equipped with a vacuum line. ${ }^{47}$ The reactant solution was maintained at room temperature using a flow of cooling water during the reaction. Before irradiation, the reaction vessel was degassed several times to remove air, followed by the introduction of 100 torr of Ar gas into the photocatalytic system. A Xe lamp (CERMAX PE300-BF, 300-W) was used as a light source, and the irradiation wavelength was controlled with a combination of a cold mirror and a water filter $(350<\lambda<800$ $\mathrm{nm}$ ). A cut-off filter (HOYA L 42) or a band pass filter (Tokina BP-44, 440 nm) was used with the aforementioned light source $(420<\lambda<800 \mathrm{~nm}$; photon flux in Figure S1, measured by EKO LS-100). The homogeneity of the solution during the reaction was maintained by agitation with a magnetic stirrer. The gases evolved were analyzed by GC (Bruker 450 GC, TCD, Ar gas, molecular sieve 13X).

All the samples were tested for photocatalytic oxygen using either $0.1 \mathrm{M} \mathrm{AgNO}_{3}$ or $0.1 \mathrm{M} \mathrm{Na}_{2} \mathrm{~S}_{2} \mathrm{O}_{8}$ as the sacrificial electron acceptor. In a typical experiment, a known amount of $\mathrm{AgNO}_{3}$ or $\mathrm{Na}_{2} \mathrm{~S}_{2} \mathrm{O}_{8}$ was dissolved in $100 \mathrm{~mL} \mathrm{H} \mathrm{H}_{2} \mathrm{O}$ and the $\mathrm{pH}$ adjusted with $\mathrm{a} \mathrm{La}_{2} \mathrm{O}_{3}$ or $\mathrm{NaOH}$ solution, respectively. Then, a 50 -mg sample was suspended in a corresponding solution and sonicated for $5 \mathrm{~min}$.
3. Results and Discussion
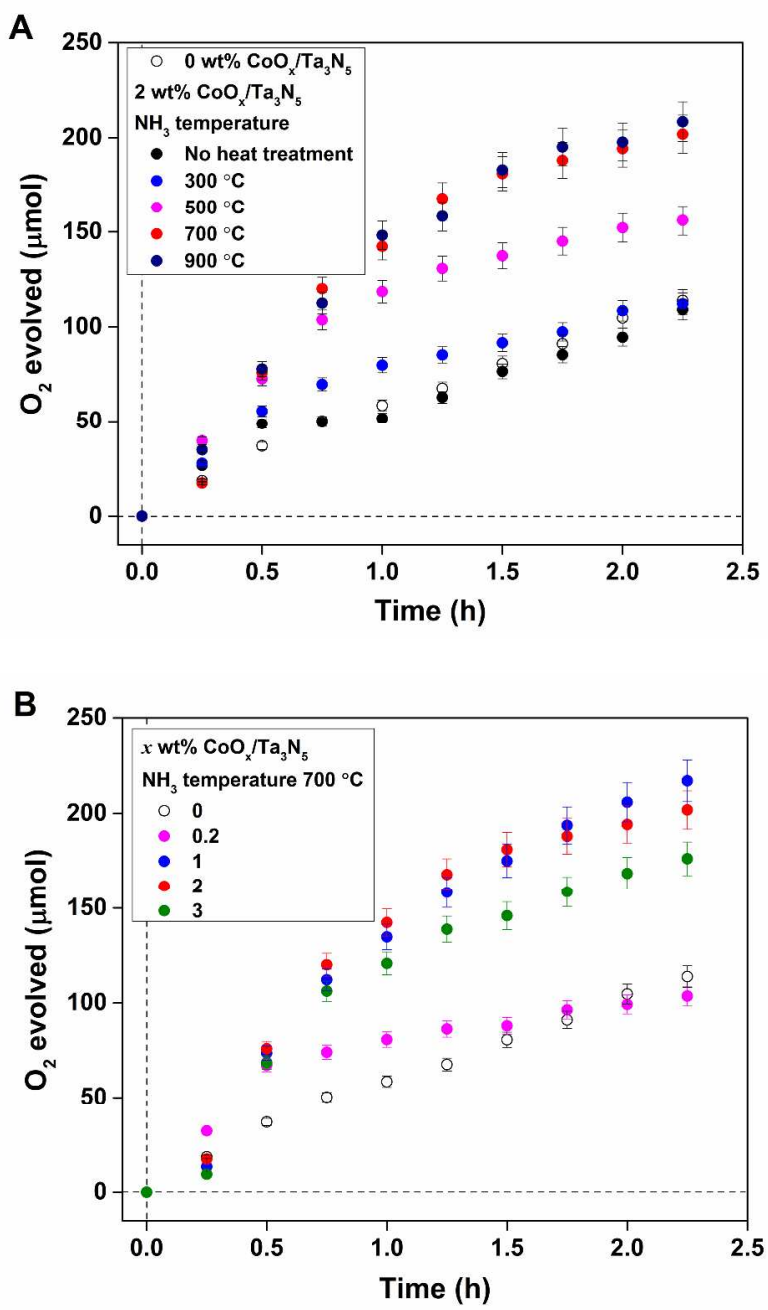

Figure 1. Time courses of photocatalytic OER using $\mathrm{CoO}_{\mathrm{x}} / \mathrm{Ta}_{3} \mathrm{~N}_{5}$ (A) treated at different temperatures under $\mathrm{NH}_{3}$ and (B) with different Co loadings $\left(10 \mathrm{mM} \mathrm{AgNO}_{3}\right.$, at $\mathrm{pH} 8.5\left(\mathrm{La}_{2} \mathrm{O}_{3}\right.$ buffer $)$ under visible light irradiation $(420<\lambda<800 \mathrm{~nm})$ ).

We previously reported the detailed photocatalytic performance of $\mathrm{Ta}_{3} \mathrm{~N}_{5}$ in the absence of catalyst. ${ }^{24}$ In this study, cobalt was introduced onto the $\mathrm{Ta}_{3} \mathrm{~N}_{5}$ surface by wet impregnation. Photocatalytic tests were conducted in the presence of $\mathrm{AgNO}_{3}$ as the sacrificial reagent and $\mathrm{La}_{2} \mathrm{O}_{3}$ as the buffer $(\mathrm{pH}$ 8.5). The amount of evolved $\mathrm{O}_{2}$ generally decreased with time because of irreversible Ag deposition onto the $\mathrm{Ta}_{3} \mathrm{~N}_{5}$ surfaces. Thus, the reaction rate was calculated using the initial slope of the plot of the amount of evolved $\mathrm{O}_{2}$ versus time. First, $2 \mathrm{wt} \%$ $\mathrm{CoO}_{\mathrm{x}} / \mathrm{Ta}_{3} \mathrm{~N}_{5}$ was pretreated under $\mathrm{NH}_{3}$ at one of the temperatures up to $900{ }^{\circ} \mathrm{C}$. The heat treatment in $\mathrm{NH}_{3}$ was critical, as shown in Figure 1A. The sample that was not heat treated did not exhibit any improvement in photocatalytic activity compared to the sample without any cobalt $\left(50 \mu \mathrm{mol} \mathrm{h}{ }^{-1}\right)$. The asimpregnated sample obviously lacked good contact between cobalt and $T a_{3} \mathrm{~N}_{5}$. The OER rate monotonically increased with increasing heating temperature, from $80 \mu \mathrm{mol} \mathrm{h}{ }^{-1}$ at $300{ }^{\circ} \mathrm{C}$ to $142 \mu \mathrm{mol} \mathrm{h}{ }^{-1}$ at $700{ }^{\circ} \mathrm{C}$; at a higher temperature of $900^{\circ} \mathrm{C}$, no further improvement of the OER rate was observed. Various loadings (0-3 wt \% Co metal base) were then evaluated for further improvement at the $\mathrm{NH}_{3}$ treatment temperature of 700 
${ }^{\circ} \mathrm{C}$. The results are presented in Figure 1B. The photocatalytic activity was enhanced upon increasing the cobalt concentration up to $2 \mathrm{wt} \%$ but slightly decreased upon further addition of cobalt. This is a general trend for powder systems due to the requirement for sites for both reduction and oxidation and potential competitive light absorption from Co species. ${ }^{25,48-50}$ To further elucidate the state of the catalyst after pretreatment, $2 \mathrm{wt} \% \mathrm{CoO}_{\mathrm{x}} / \mathrm{Ta}_{3} \mathrm{~N}_{5}$ treated at $700{ }^{\circ} \mathrm{C}$ under $\mathrm{NH}_{3}$ was selected for further study unless otherwise noted.

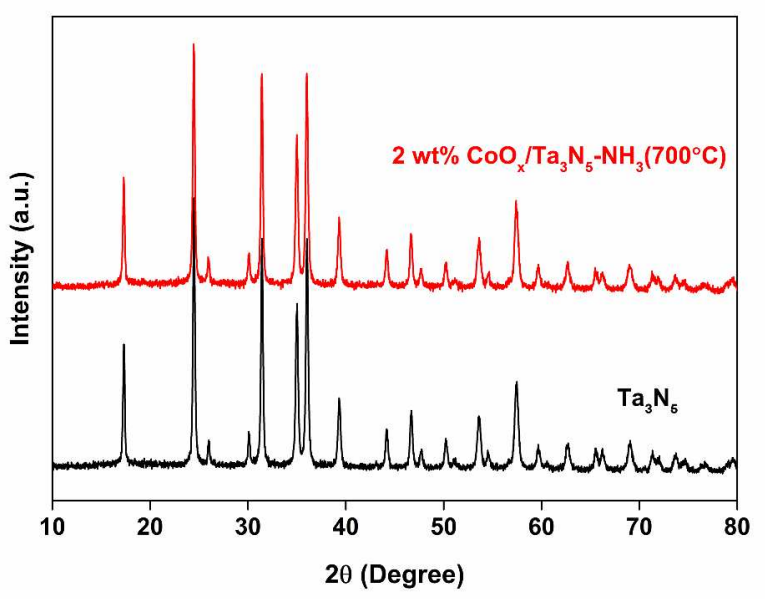

Figure 2. XRD patterns of bare $\mathrm{Ta}_{3} \mathrm{~N}_{5}$ and $\mathrm{CoO}_{\mathrm{x}} / \mathrm{Ta}_{3} \mathrm{~N}_{5}$ after nitridation at $700{ }^{\circ} \mathrm{C}$.

The XRD patterns of $\mathrm{Ta}_{3} \mathrm{~N}_{5}$ and $\mathrm{CoO}_{\mathrm{x}} / \mathrm{Ta}_{3} \mathrm{~N}_{5}$ are compared in Figure 2. The d-spacings observed for the initial $\mathrm{Ta}_{3} \mathrm{~N}_{5}$ material correspond to a single phase with an orthorhombic structure $(\mathrm{Cmcm})$. The cobalt-nitrogen system has been reported to contain many phases. These vary with increasing nitrogen concentration from a Co-N solid solution (cubic $\left(>425{ }^{\circ} \mathrm{C}\right.$ ), $\mathrm{F}_{\mathrm{m} 3 \mathrm{~m}}$ or hexagonal $\left(<425{ }^{\circ} \mathrm{C} \text { ), } \mathrm{P}_{63 / \mathrm{mc}}\right)^{51-52}$ to $\mathrm{Co}_{4} \mathrm{~N}$ (cubic, $\mathrm{P}_{\mathrm{m}-}$ ${ }_{3 \mathrm{~m}}$ ), ${ }^{53} \mathrm{Co}_{2} \mathrm{~N}$ (orthorhombic, $\mathrm{P}_{\mathrm{mnn}}$ ), ${ }^{54}$ or $\mathrm{CoN}$ (cubic, $\mathrm{F}_{-43 \mathrm{~m}}(\mathrm{ZnS}$ type) or $\mathrm{F}_{\mathrm{m}-3 \mathrm{~m}}(\mathrm{NaCl}$ type) $) .{ }^{55}$ The formation of such a cobaltnitrogen solid solution as well as $\mathrm{CoO}_{\mathrm{x}}$ was not evident in the XRD patterns because an insufficient amount of cobalt was deposited.

Raman spectra of $\mathrm{Ta}_{3} \mathrm{~N}_{5}$ and $\mathrm{CoO}_{\mathrm{x}} / \mathrm{Ta}_{3} \mathrm{~N}_{5}$ are presented in Figure 3. Because there is only limited literature describing the Raman modes of $\mathrm{Ta}_{3} \mathrm{~N}_{5}$, a detailed assignment for $\mathrm{Ta}_{3} \mathrm{~N}_{5} \mathrm{Ra}$ man modes based on theoretical calculations was previously performed in our recent study. ${ }^{21,56}$ To summarize, the theory predicted for the orthorhombic allotrope $(\mathrm{Cmcm})$ of $\mathrm{Ta}_{3} \mathrm{~N}_{5}$ a total of 24 Raman-active modes $\left(8 \mathrm{~A}_{\mathrm{g}}+16 \mathrm{~B}_{\mathrm{g}}\right)$. The experimental spectrum of $\mathrm{Ta}_{3} \mathrm{~N}_{5}$ only displayed 14 peaks: 138,230 , $269,522,599,863$, and $895 \mathrm{~cm}^{-1}$ vibrations assigned to $A_{g}$ modes and $125,169,181,402,495,748$, and $829 \mathrm{~cm}^{-1}$ vibrations assigned to $\mathrm{B}_{\mathrm{g}}$ modes. The spectrum of $\mathrm{CoO}_{\mathrm{x}} / \mathrm{Ta}_{3} \mathrm{~N}_{5}$ clearly showed the appearance of three additional peaks at 193,475 , and $678 \mathrm{~cm}^{-1}$. The vibration at $193 \mathrm{~cm}^{-1}$ is characteristic of a $\left[\mathrm{CoO}_{4}\right]$ unit, as already observed for the vibration of the tetrahedral site in $\mathrm{Co}_{3} \mathrm{O}_{4}$ spinel. ${ }^{57}$ The band at $475 \mathrm{~cm}^{-1}$ is attributed to a Co-O stretching vibration, and the band at 671 $\mathrm{cm}^{-1}$ is attributed to the vibration of a $\left[\mathrm{CoO}_{6}\right]$ unit, already observed for crystalline $\mathrm{CoO}$ and $\mathrm{Co}_{3} \mathrm{O}_{4}$ solids. ${ }^{35,58-59}$ Furthermore, no vibrations originating from the metallic cobalt nanocrystallites could be observed. Indeed, group theory predicts no active Raman modes for the fcc lattice, whereas for the hcp lattice, only one Raman mode $\left(\mathrm{E}_{\mathrm{g}}\right)$ is active and reported with a wavenumber of $130 \mathrm{~cm}^{-1}$. The latter could not be observed because it overlaps with the intense $A_{g}$ mode of $T_{3} N_{5}$ located at $138 \mathrm{~cm}^{-1}$.

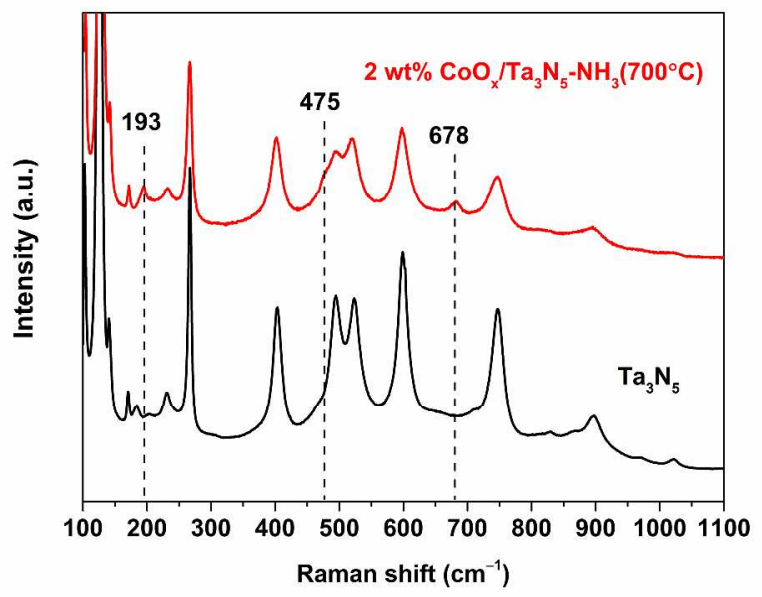

Figure 3. Raman spectra of $\mathrm{Ta}_{3} \mathrm{~N}_{5}$ and $\mathrm{CoO}_{\mathrm{x}} / \mathrm{Ta}_{3} \mathrm{~N}_{5}$ after nitridation at $700{ }^{\circ} \mathrm{C}$.

X-ray absorption spectroscopy (XAS) with sensitive fluorescence detection was used to unveil the local environment of the cobalt. Cobalt K-edge XANES spectra for the reference hexagonal cobalt foil and $\mathrm{CoO}_{\mathrm{x}} / \mathrm{Ta}_{3} \mathrm{~N}_{5}$ after impregnation and after $\mathrm{NH}_{3}$ treatment at $700{ }^{\circ} \mathrm{C}$ are presented in Figure $4 \mathrm{~A}$. The analysis of the pre-edge region at approximately $7710 \mathrm{eV}$ is very informative as to the position and intensity of the localized transitions observed at the $\mathrm{K}$ pre-edge, which are characteristic of the oxidation state of the metal and the geometry of its environment. ${ }^{61-62}$

For $\mathrm{CoO}_{\mathrm{x}} / \mathrm{Ta}_{3} \mathrm{~N}_{5}$ after impregnation, although the signal was rather noisy in this region, a weak absorption peak was observed at $7009.5 \mathrm{eV}$. The origin of the latter absorption is usually related to the presence of quadrupolar $\mathrm{Co}(1 \mathrm{~s}) \rightarrow$ $\mathrm{Co}(3 \mathrm{~d})$ transitions within an octahedral field. After the material was subjected to nitridation at $700{ }^{\circ} \mathrm{C}$, the pre-edge was drastically modified, and its shape became similar to that observed for the cobalt metallic foil. These observations were consistent with the large decrease in the white-line intensity upon nitridation treatment, which is evidence of a quantitative reduction of cobalt. However, both the pre-edge and white line did not reach the same levels as those observed for the cobalt metallic foil, indicating that cobalt atoms remained partially oxidized. To the best of our knowledge, only two experimental studies have reported the XANES spectrum of $\mathrm{Co}^{\mathrm{III}} \mathrm{N}$, either as a rock-salt-type ${ }^{63}$ or a zinc-blende-type structure. ${ }^{64}$ The formation of $\mathrm{CoN}$ ( $\mathrm{ZnS}$ type) was excluded for $\mathrm{CoO}_{\mathrm{x}} / \mathrm{Ta}_{3} \mathrm{~N}_{5}$ because of the absence of the intense and well-resolved transition $\mathrm{Co}(1 \mathrm{~s}) \rightarrow \mathrm{Co}(3 \mathrm{~d}-4 \mathrm{p})$, related to the local tetrahedral symmetry around the cobalt atoms (Wyckoff position 4a). A minor presence of $\mathrm{CoN}$ with a rock-salt-type structure cannot be ruled out because the pure compounds display a rather intense white line with a quasi-inexistent pre-edge transition (Co in $\mathrm{O}_{\mathrm{h}}$ symmetry). For the other crystalline cobalt nitrides $\left(\mathrm{Co}_{4} \mathrm{~N}, \mathrm{Co}_{3} \mathrm{~N}\right.$, and $\left.\mathrm{Co}_{2} \mathrm{~N}\right)$, there are no XANES spectra reported in the literature, so calculations performed with FDMNES code were used to compare the experimental spectrum of $\mathrm{CoO}_{\mathrm{x}} / \mathrm{Ta}_{3} \mathrm{~N}_{5}$ with simulated absorption spectra of cobalt metal, (hydro)oxides, and nitrides (Figure S2A-C). All the major 
absorption features of the reference compounds were well represented although slight shifts in certain energy positions were observed (especially for the pre-edge region). Thus, the presence of the $\mathrm{Co}_{4} \mathrm{~N}, \mathrm{Co}_{3} \mathrm{~N}$, and $\mathrm{Co}_{2} \mathrm{~N}$ phases could be excluded because none of their main absorption features could be identified in the $\mathrm{CoO}_{\mathrm{x}} / \mathrm{Ta}_{3} \mathrm{~N}_{5}$ spectrum (Figure S2B). The best match of the nitrided $\mathrm{CoO}_{\mathrm{x}} / \mathrm{Ta}_{3} \mathrm{~N}_{5}$ spectrum was, however, obtained by a linear combination of the $\mathrm{CoOOH}$ (19 wt.\%) and $\mathrm{Co}(\mathrm{OH})_{2}(30$ wt.\%) theoretical spectra and the cobalt metallic foil spectra (51 wt.\%) (Figure S2D).

The analysis of the Co K-edge $\mathrm{k}^{2}$-weighted EXAFS signal further substantiated the XANES results. First, the EXAFS spectrum of the cobalt metallic foil (hcp) was fitted within a krange of $[3.3 ; 12] \AA^{-1}$. The distinction between the cubic and hexagonal crystal systems using EXAFS requires the investigation of the 3.5-5 $\AA$ R-interval of the Fourier transform. ${ }^{65}$ Thus, an extensive R-range $([1 ; 5.1] \AA)$ was fitted using single and multiple scattering paths calculated from the crystal structure of either hexagonal or cubic metallic cobalt. The parameterization of the latter scattering paths was as follows: a single shift of energy was used, all amplitudes were adjusted by the amplitude reduction factor $\left(\mathrm{S}_{\mathrm{o}}\right)$, the variation of distances was calculated by adjusting the cell parameters of the considered lattice, the disorder for each single scattering paths was fitted with an independent mean square displacement parameter, for multiple scattering paths (triangular and collinear pathways) it was modelled by linear combinations of the mean square displacement parameters of the relevant single scattering paths.

When the parameters of the latter models were adjusted to the EXAFS spectrum for the reference metallic foil, excellent agreement between theory and experiments was obtained, especially with the hexagonal model (R-factor $=6 \times 10^{-5}$, Figure $4 \mathrm{~B}, \mathrm{C}$ and Table S1). The clear improvement in the reduced chi-squared value for the latter hexagonal model $\left(\chi_{\mathrm{v}}^{2}(\mathrm{hcp})=\right.$ $133)$ compared with a standard cubic model $\left(\chi_{\mathrm{v}}^{2}(\mathrm{fcc})=1108\right)$ was noteworthy and was explained by the better fitting of the higher-order shell. The amplitude-reduction factor $\left(\mathrm{S}_{\mathrm{o}}\right)$ was determined to be $0.87 \pm 0.04$ and was fixed for the following EXAFS fittings.

The useful k-range for $\mathrm{CoO}_{\mathrm{x}} / \mathrm{Ta}_{3} \mathrm{~N}_{5}$ after impregnation was rather limited because the data were too noisy above $9 \AA^{-1}$. Thus, the impregnated $T a_{3} \mathrm{~N}_{5}$ was analyzed with a restricted number of parameters within a k-range of [3.3: 7.45] $\AA^{-1}$ and within an R-range of $[0.8 ; 4.6] \AA$ (8 parameters for 10 independent points, Figure $4 \mathrm{~B}, \mathrm{C}$ and Table S1). The first neighbor contribution was fitted with a total of $6 \pm 1$ oxygen atoms at $2.13 \pm 0.02 \AA$, which confirmed the presence of cobalt in an octahedral environment. The second and third coordination shells were fitted using $1.7 \pm 0.5$ cobalt atoms at $2.85 \pm 0.03 \AA$ and $2 \pm 1$ cobalt atoms at $3.76 \pm 0.03 \AA$. Although the quantification of cobalt neighboring atoms was not reliable because their mean square displacement parameters were fixed due to parameter correlations, these results at least indicate that the cobalt nitrate displayed a certain degree of polycondensation after its impregnation. To conclude, the structure of $\mathrm{CoO}_{\mathrm{x}} / \mathrm{Ta}_{3} \mathrm{~N}_{5}$ as impregnated was consistent with the presence of an amorphous cobalt oxyhydroxide spread on the surface of $\mathrm{Ta}_{3} \mathrm{~N}_{5}$.
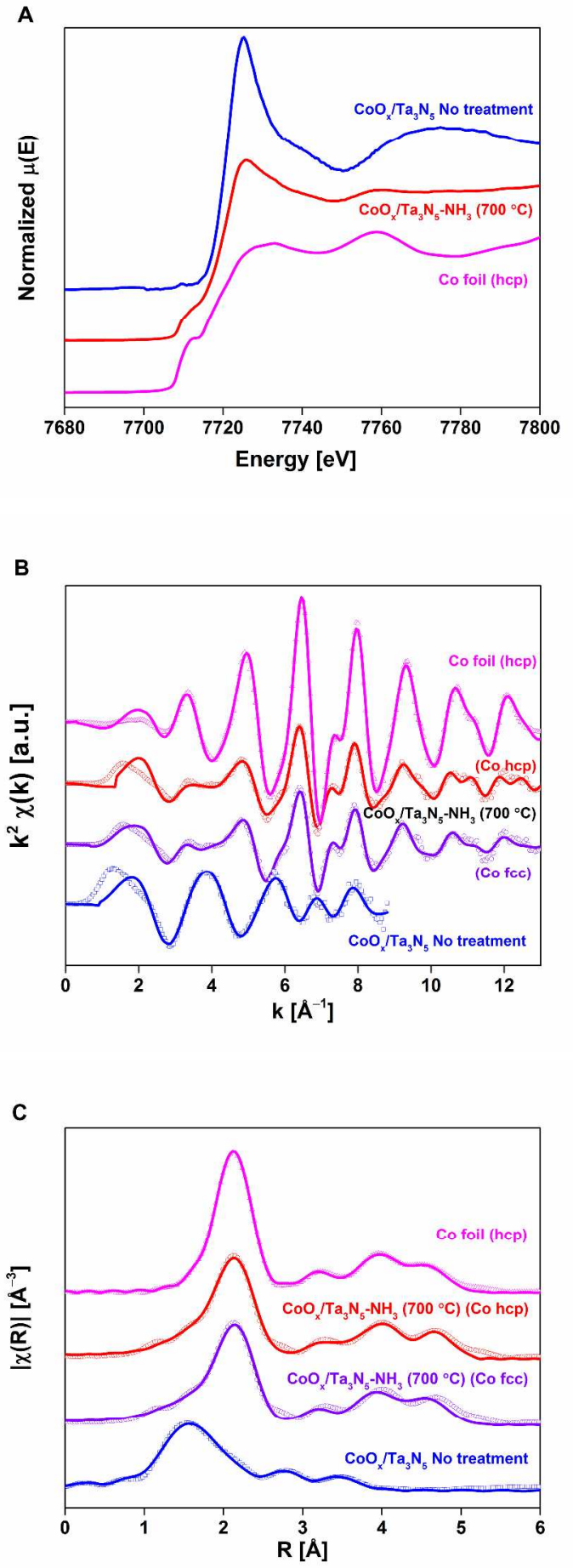

Figure 4. (A) XANES spectra, (B) EXAFS $\mathrm{k}^{2} \cdot \chi(\mathrm{k})$ functions and (C) the related Fourier transforms for a cobalt metallic foil (hcp), 2 wt.\% cobalt content loaded on the surface of $\mathrm{Ta}_{3} \mathrm{~N}_{5}$ after impregnation $\left(\mathrm{CoO}_{\mathrm{x}} / \mathrm{Ta}_{3} \mathrm{~N}_{5}\right)$ and after nitridation at $700{ }^{\circ} \mathrm{C}$ $\left(\mathrm{CoO}_{\mathrm{x}} / \mathrm{Ta}_{3} \mathrm{~N}_{5}-\mathrm{NH}_{3}\right)$. The open symbols are the experimental data while the solid lines are the fit results. The fit results using the hep or fcc model are both shown for $\mathrm{CoO}_{\mathrm{x}} / \mathrm{Ta}_{3} \mathrm{~N}_{5}-\mathrm{NH}_{3}$ sample. 
A

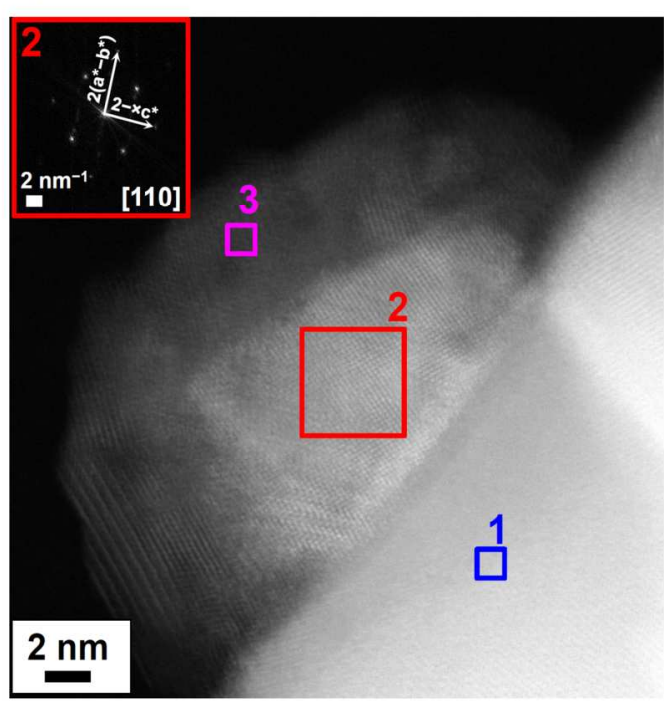

B

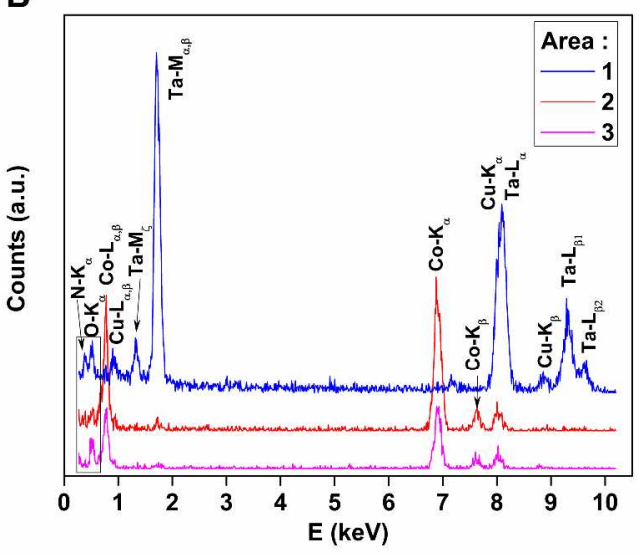

Figure 5. (A) Dark-field HR-STEM for core-shell agglomerated cobalt nanoparticles. The inset shows the FFT results of the core region and depicts a characteristic fcc pattern viewed along the [110] zone axis, (B) X-ray fluorescence spectra of $\mathrm{Ta}_{3} \mathrm{~N}_{5}$ (1), the core (2) and the shell (3) of an agglomerate as depicted on (B).

A preliminary qualitative comparison of the EXAFS spectra of the metallic cobalt foil (hcp) with $\mathrm{CoO}_{\mathrm{x}} / \mathrm{Ta}_{3} \mathrm{~N}_{5}$ after nitridation revealed striking similarities for the $\mathrm{k}$ value above 4 $\AA^{-1}$ (Figure 4B, C). For k values less than $4 \AA^{-1}$, the oscillation of the metallic phase appears modulated by the presence of a light backscatterer. Hence, the models for the EXAFS fitting of $\mathrm{CoO}_{\mathrm{x}} / \mathrm{Ta}_{3} \mathrm{~N}_{5}$ after nitridation involve either the hexagonal or cubic model for metallic cobalt, with one additional single scattering path due to oxygen atoms (k-range of $[3.3 ; 11.5] \AA^{-1}$ and R-range of $[1 ; 5.1] \AA$ ). The light atoms $\mathrm{N}$ and $\mathrm{O}$ were treated as one single type of ligand because EXAFS is not capable of distinguishing between scattering atoms with close atomic numbers. ${ }^{66}$ The oscillation amplitude for each scattering path of the metallic phase was fitted by keeping the amplitude-reduction factor $\mathrm{S}_{0}$ constant and adjusting a single amplitude parameter. Both the cubic and hexagonal model provide acceptable agreement with the experimental data, although not as good as that obtained with the reference Co foil (Rfactor $(\mathrm{fcc})=9 \times 10^{-3}, \mathrm{R}$-factor(hcp) $=4 \times 10^{-3}, \chi_{\mathrm{v}}^{2}(\mathrm{fcc})=45$, and $\left.\chi_{\mathrm{v}}^{2}(\mathrm{hcp})=25\right)$. A clear-cut distinction between the hex- agonal and cubic Bravais lattices is thus not possible in this case. The latter issue could be evidence of an hcp and fcc polytype mixture or possibly the presence of stacking faults in the close-packing arrangement of atoms in nanocrystallites, which was previously investigated by Longo et al. ${ }^{67}$ The coordination number of the first Co-Co bond was $6 \pm 1$, which confirms the formation of small nanoparticles. The estimation of the particle size was prevented by a non-negligible presence of the light scatterer $(\mathrm{N}(\mathrm{Co}-\mathrm{O} / \mathrm{N}) \approx 3.7 \pm 1)$ at $2.04 \pm 0.08 \AA$. Note that none of the attempts to fit the EXAFS spectrum of $\mathrm{CoO}_{\mathrm{x}} / \mathrm{Ta}_{3} \mathrm{~N}_{5}$ after nitridation with the crystal structures of the cobalt nitrides $\left(\mathrm{Co}_{\mathrm{n}} \mathrm{N}, \mathrm{n}=1-4\right)$ led to any acceptable agreement. The only possibilities left to explain the presence of light atoms in the vicinity of metallic cobalt was a partial surface oxidation by $\mathrm{O}_{2}$ and/or the presence of a Co-N solid solution within the metallic cobalt.

HAADF-STEM was used to further investigate the $\mathrm{CoO}_{\mathrm{x}} / \mathrm{Ta}_{3} \mathrm{~N}_{5}$ structure after nitridation. The micrograph presented in Figures 5A and S3A shows a typical example of a large agglomerate deposited onto the surface of $\mathrm{Ta}_{3} \mathrm{~N}_{5}$. The acquisition of hundreds of micrographs revealed that such agglomerates were randomly dispersed on the surface of $\mathrm{Ta}_{3} \mathrm{~N}_{5}$ and had an average size of $15 \pm 2.5 \mathrm{~nm}$. Elemental mapping of selected areas confirmed the presence of cobalt atoms as the main component, although oxygen atoms were also detected (Figure S3A). Observations at higher magnification indicate that the agglomerates are composed of small crystallites with a range of sizes between 2 and $4 \mathrm{~nm}$ (Figure 5A). A fast-Fourier transform (FFT) of the crystalline region revealed a characteristic pattern of a cubic lattice viewed along the [110] zone axis (Figure 5A inset). The calculated cell parameter (3.55 $\AA$ ) was consistent with the reported cell parameter of fcc metallic cobalt $(\mathrm{a}=3.548 \AA)$. This finding was also consistent with the XAS results, which indicated the presence of metallic cobalt was proposed for $\mathrm{CoO}_{\mathrm{x}} / \mathrm{Ta}_{3} \mathrm{~N}_{5}$ after nitridation.

Interestingly, a difference was regularly noted between the surface and core of the agglomerates in the HAADF-STEM micrographs (Figure 5A): the core often appeared brighter, whereas the shell was darker. As dark-field STEM is mostly sensitive to the atomic number of atoms, the darker region suggested an enrichment of oxygen atoms. To further confirm this finding, EDX point analysis was performed on the three areas indicated in Figure 5A. The resultant X-ray fluorescence spectra of each area are presented in Figure 5B. For the $\mathrm{Ta}_{3} \mathrm{~N}_{5}$ region (area 1), the nitrogen $\left(\mathrm{K}_{\alpha}\right)$ and tantalum $\left(\mathrm{L}_{\alpha, \beta}, \mathrm{M}_{\alpha, \beta}\right)$ fluorescence lines were indeed observed. The noticeable presence of the $\mathrm{K}_{\alpha}$ fluorescence line of oxygen in this region also indicated a slight oxidation of the $\mathrm{Ta}_{3} \mathrm{~N}_{5}$ surface. In the agglomerate region (area 2,3), the cobalt fluorescence lines $\left(\mathrm{K}_{\alpha, \beta}, \mathrm{L}_{\alpha, \beta}\right)$ were also easily observed. Noticeably, the shell region (area 3) clearly displayed a more intense $\mathrm{K}_{\alpha}$ fluorescence line of the oxygen atoms than the core (area 2). Additionally, an STEM-EELS elemental line-scan profile was acquired from the surface to the bulk of one agglomerate (Figure $\mathrm{S} 3 \mathrm{~B})$. The spectra of the shell and core regions were summed separately and are displayed in Figure S3C. A comparison of the intensity ratios of the $\mathrm{O}$ K-edge to the Co L-edge in the shell and core regions indicates a stronger oxidation of the shell.

To further refine the chemical state of the cobalt species deposited onto the $\mathrm{Ta}_{3} \mathrm{~N}_{5}$, the samples were analyzed using Xray photoelectron spectroscopy (XPS) (Figure 6). Careful con- 
siderations must be taken to assign the XPS peaks of cobalt $2 p$ core levels because of the close binding energies of the cobalt oxidation states, multiplet splitting, and the presence of satellites. ${ }^{68}$ The cobalt core-level spectrum of crystalline $\mathrm{CoO}$ displays two main peaks at binding energies of $797\left(2 p_{3 / 2}\right)$ and $782 \mathrm{eV}\left(2 \mathrm{p}_{3 / 2}\right)$ and two satellites at 786.5 and $802 \mathrm{eV}$. Crystalline $\mathrm{CoO}$ and $\mathrm{Co}_{3} \mathrm{O}_{4}$ are more easily distinguished by their satellite peaks rather than by their main core levels. Indeed, the satellite peak near the $2 \mathrm{p}_{3 / 2}$ state for $\mathrm{Co}_{3} \mathrm{O}_{4}$ is $2 \mathrm{eV}$ higher $(804 \mathrm{eV})$ than that of $\mathrm{CoO}(802 \mathrm{eV})$. However, the satellite peak near the $2 \mathrm{p}_{1 / 2}$ state for $\mathrm{CoO}(787 \mathrm{eV})$ is slightly higher than that of $\mathrm{Co}_{3} \mathrm{O}_{4}(785 \mathrm{eV}) .{ }^{58,68}$ The spectra of $\mathrm{CoO}_{\mathrm{x}} / \mathrm{Ta}_{3} \mathrm{~N}_{5}$ samples prepared at various nitration temperatures all reveal two main peaks at $797.5\left(2 \mathrm{p}_{1 / 2}\right)$ and $782 \mathrm{eV}\left(2 \mathrm{p}_{3 / 2}\right)$ and two satellites at 804 and $787 \mathrm{eV}$. Because of the presence of the satellite peaks, the oxidation state of the cobalt atoms was attributed, based on previous literature, to a mixture of $\mathrm{Co}^{\mathrm{II}}$ and $\mathrm{Co}^{\mathrm{III}}$ states in accordance with XAS results. The $2 \mathrm{p}_{1 / 2}(778$ $\mathrm{eV}$ ) core levels of the cobalt metallic state was also present as a weak shoulder of the main peaks located at $782 \mathrm{eV}$ for $\mathrm{CoO}_{\mathrm{x}} / \mathrm{Ta}_{3} \mathrm{~N}_{5}$ after nitridation (highlighted in Figure 6). ${ }^{68} \mathrm{An}$ estimation of the inelastic mean free path of the photoelectron emitted in crystalline $\mathrm{Co}(\mathrm{OH})_{2}$ due to aluminum $\mathrm{K}_{\alpha}$ radiation was calculated to be in the range of 1 to $2 \mathrm{~nm}^{69}$ Considering an average shell thickness of $\approx 6 \mathrm{~nm}$, as observed by STEM, it is reasonable that the signal associated with metallic is weak. By extension, this finding also implies that all the metallic cobalt nanocrystallites were almost fully covered by an oxide or oxyhydroxide layer.

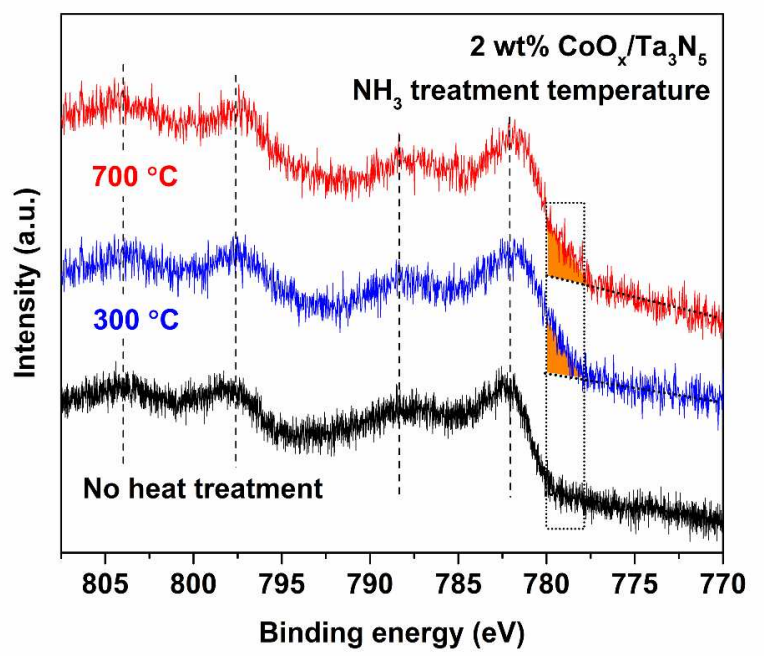

Figure 6. Co $2 p$ XPS spectra of $\mathrm{CoO}_{x} / \mathrm{Ta}_{3} \mathrm{~N}_{5}$ synthesized at different temperature.

Comprehensive characterization was performed on $\mathrm{CoO}_{\mathrm{x}} / \mathrm{Ta}_{3} \mathrm{~N}_{5}$ synthesized by wet impregnation followed by nitridation. An agglomerated core-shell-like structure of cobalt was observed with metallic cobalt in the core and cobalt oxide in the shell. Although, the distinction between the cubic and hexagonal lattice using EXAFS was successful for a reference cobalt metallic foil, it was not possible to conduct the same identification for $\mathrm{CoO}_{\mathrm{x}} / \mathrm{Ta}_{3} \mathrm{~N}_{5}$ after nitridation. However, electron microscopy study did show for a few spots - where crystallites agglomeration was limited- a cubic lattice. The fact that the hexagonal lattice was not found by electron microscopy do not prove its absence. Indeed, the results of X-ray ab- sorption spectroscopy are statistically more relevant as it provides the average atomic and electronic structure of all cobalt atoms. Thus, a mixture of cubic and hexagonal lattice seems a more reasonable description of the crystal nature of the cobalt metallic core. Studies discussing the characteristics of cobalt on the surface of photocatalysts are very limited. On the surface of $\mathrm{LaTiO}_{2} \mathrm{~N}$, which was synthesized using a similar procedure followed by oxidation, the cobalt species was assigned to mixed cobalt oxide based on the d-spacing of HRTEM and XPS spectra. ${ }^{25}$ Comparison with the XRD pattern of the nitridation of pure cobalt nitrate suggested that cobalt was initially (after nitridation but before oxidation) in the form of metallic cobalt. Our finding confirms the presence of metallic cobalt with slight oxidation on the surface. In addition, no form of cobalt nitride was observed in our case, consistent with previous observations for cobalt on a $\mathrm{Ta}_{3} \mathrm{~N}_{5}$ film. ${ }^{30}$ The cubic phase of $\mathrm{Co}_{5 \cdot 47} \mathrm{~N}$ has been observed on a $\mathrm{Ta}_{3} \mathrm{~N}_{5}$ film by comparing the glancing incidence XRD pattern of Co metal and that of $\mathrm{CoO}_{\mathrm{x}} / \mathrm{Ta}_{3} \mathrm{~N}_{5}$, both after nitridation.

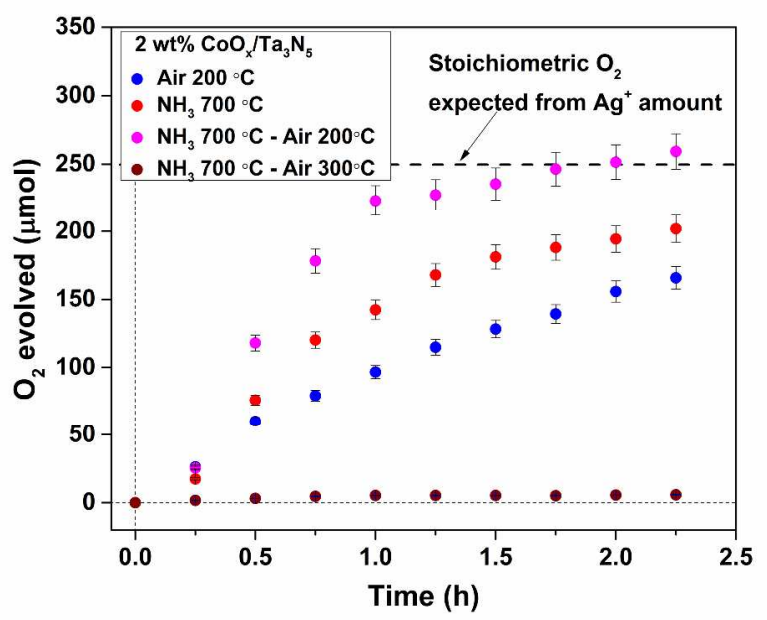

Figure 7. Time course of photocatalytic OER on as-impregnated $\mathrm{CoO}_{\mathrm{x}} / \mathrm{Ta}_{3} \mathrm{~N}_{5}$ treated at $200{ }^{\circ} \mathrm{C}$ for $1 \mathrm{~h}$, and on nitrided $\mathrm{CoO}_{\mathrm{x}} / \mathrm{Ta}_{3} \mathrm{~N}_{5}$ with and without oxidation at 200 and $300{ }^{\circ} \mathrm{C}$ for $1 \mathrm{~h}(10 \mathrm{mM}$ $\mathrm{AgNO}_{3}$, at $\mathrm{pH} 8.5\left(\mathrm{La}_{2} \mathrm{O}_{3}\right.$ buffer $)$ under visible light irradiation $(420<\lambda<800 \mathrm{~nm}))$.

It is well documented that the oxide states of cobalt $\left(\mathrm{CoO}_{\mathrm{x}}\right.$ or $\left.\mathrm{Co}_{3} \mathrm{O}_{4}\right)$ are the active species for the OER and are obtained by heat treatment in air (oxidation). In the presence of $\mathrm{Ta}_{3} \mathrm{~N}_{5}$, heat treatment should be conducted under $\mathrm{NH}_{3}$ because of its sensitivity to oxidation. The heat treatment was not only intended to alter the cobalt oxidation state but also to improve the contact between $\mathrm{CoO}_{\mathrm{x}}$ and $\mathrm{Ta}_{3} \mathrm{~N}_{5}$ for better hole transfer. Because the characterization indicates that cobalt was in the metallic state in the core and oxidized on the surface, it is of particular interest to study the active species for the photocatalytic OER on $\mathrm{CoO}_{\mathrm{x}} / \mathrm{Ta}_{3} \mathrm{~N}_{5}$. The $\mathrm{NH}_{3}$-treated $\mathrm{CoO}_{\mathrm{x}} / \mathrm{Ta}_{3} \mathrm{~N}_{5}$ was further oxidized at a mild condition of $200{ }^{\circ} \mathrm{C}$ for various durations $(1,3$, and $5 \mathrm{~h}$ ), and the photocatalytic activity is shown in Figure S4. The photocatalytic activity was significantly improved after oxidation (143 to $222 \mu \mathrm{mol} \mathrm{h}{ }^{-1}$ ). The quantum efficiency using a band pass filter $(\sim 440 \mathrm{~nm})$ was $19.4 \%$, one of the highest reported for photocatalytic OER using $\mathrm{Ag}^{+}$as a sacrificial electron acceptor. Longer oxidation times for 3 and $5 \mathrm{~h}$ also led to improvement of photocatalytic activity over the sample without mild oxidation but caused a slight decrease compared to treatment for $1 \mathrm{~h}$ (Figure S4). Treatment at 300 
${ }^{\circ} \mathrm{C}$ completely reduced the photocatalytic activity (Figure 7). Thus, a higher oxidation temperature was detrimental for $\mathrm{Ta}_{3} \mathrm{~N}_{5}$ (i.e., $\mathrm{Ta}_{3} \mathrm{~N}_{5}$ is oxidized, at least on the surface) as confirmed by thermal gravimetric analysis measurement of $T a_{3} \mathrm{~N}_{5}$ in flowing air (Figure S5). The treatment under $\mathrm{N}_{2}$ (instead of air) at $200^{\circ} \mathrm{C}$ did not improve the photocatalytic activity as shown in Figure S6, confirming important role of oxidative treatment after nitridation. High temperature treatment to ensure intimate contact at cobalt species- $\mathrm{Ta}_{3} \mathrm{~N}_{5}$ interface, followed by creation of more active electrocatalyst (metallic cobalt oxidation), seem to be effective. We have discussed the significant impact of the surface layer extensively in our previous work. ${ }^{24}$ The direct heat treatment of impregnated $\mathrm{CoO}_{\mathrm{x}} / \mathrm{Ta}_{3} \mathrm{~N}_{5}$ under air at $200{ }^{\circ} \mathrm{C}$ without $\mathrm{NH}_{3}$ treatment (see Figure 7) did not drastically improve the photocatalytic activity, emphasizing the important role of high temperature treatment without altering $\mathrm{Ta}_{3} \mathrm{~N}_{5}$ states.

To eliminate the possibility of $\mathrm{Ag}$ effects and to enable characterization of the samples after the reaction, the photocatalytic activity of $\mathrm{CoO}_{\mathrm{x}} / \mathrm{Ta}_{3} \mathrm{~N}_{5}$ with and without mild oxidation was also tested using a different sacrificial reagent (i.e., $0.1 \mathrm{M} \mathrm{Na}_{2} \mathrm{~S}_{2} \mathrm{O}_{8}$ ). As observed in Figure S6, the photocatalytic activity decreased, most likely because of the different mechanisms of reduction in $\mathrm{AgNO}_{3}$ and $\mathrm{Na}_{2} \mathrm{~S}_{2} \mathrm{O}_{8}$. Reduction of $\mathrm{Ag}^{+}$ ion is a one-electron process, whereas that of $\mathrm{Na}_{2} \mathrm{~S}_{2} \mathrm{O}_{8}$ is a rather complex reduction involving a two-electron process. Complexity further arises also from the reported doublecurrent effect. ${ }^{70}$ The trend for the photocatalytic OER is, however, similar in these two sacrificial reagents, i.e., mild oxidation improved the photocatalytic activity (40 to $67 \mu \mathrm{mol} \mathrm{h}^{-1}$ in the case of $\mathrm{Na}_{2} \mathrm{~S}_{2} \mathrm{O}_{8}$ ). This result confirms the beneficial effects of mild oxidation on photocatalytic activity for OER of the nitrided sample. The photocatalytic activity improvement after the mild oxidation suggests that $\mathrm{CoO}_{x}$ sites are indeed the active sites for the OER. In addition, photocatalytic OER activity of oxidized $\mathrm{CoO}_{\mathrm{x}} / \mathrm{Ta}_{3} \mathrm{~N}_{5}$ shows an excellent stability for $10 \mathrm{~h}$ at $100 \mu \mathrm{mol} \mathrm{h}{ }^{-1}$ as shown in Figure S8.

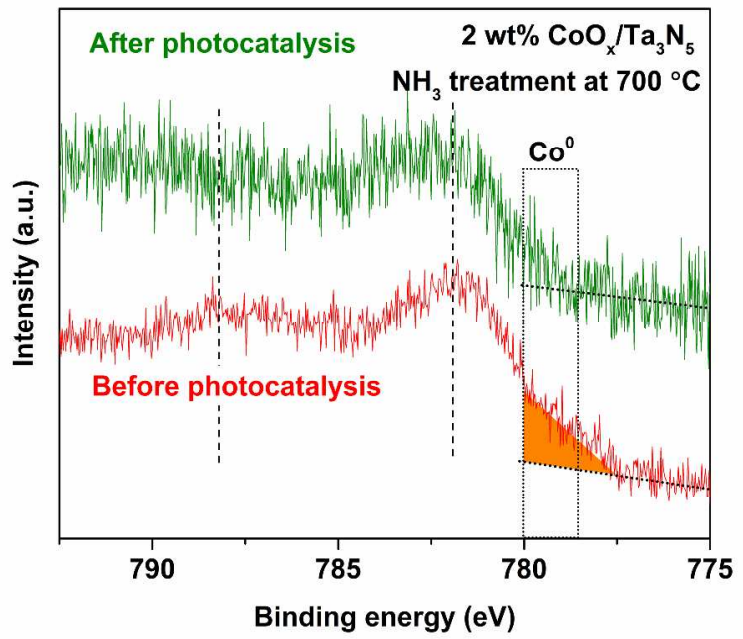

Figure 8. Co $2 p$ XPS spectra of nitrided $\mathrm{CoO}_{x} / \mathrm{Ta}_{3} \mathrm{~N}_{5}$ before and after photocatalytic reaction in $0.1 \mathrm{M} \mathrm{Na}_{2} \mathrm{~S}_{2} \mathrm{O}_{8}$ as sacrificial reagent.

The XPS spectra of the sample before and after the photocatalytic test are compared in Figure 8. The minor shoulder peak due to the presence of the metallic Co was no longer observed, in contrast to the nitrided sample. As discussed pre- viously, the cobalt core-level spectrum displays a mixture of $\mathrm{Co}^{\mathrm{II}}$ and $\mathrm{Co}^{\mathrm{III}}$. The oxidation of cobalt likely occurred during photocatalysis. In addition, the STEM image with elemental mapping of the spent sample $\left(\mathrm{CoO}_{\mathrm{x}} / \mathrm{Ta}_{3} \mathrm{~N}_{5}\right.$ after the photocatalytic reaction using $\mathrm{Na}_{2} \mathrm{~S}_{2} \mathrm{O}_{8}$ as a sacrificial reagent) no longer indicated the presence of metallic cobalt (Figure S9).

The oxidation of cobalt at the potential of OER $(>1.23$ $\mathrm{V}_{\mathrm{RHE}}$ ) is reasonable as long as an interface with water is present. Accordingly, mild oxidation at $200{ }^{\circ} \mathrm{C}$ enhanced the photocatalytic performance. The results clearly suggest that the oxidized Co species provides active sites and that a metallic state is not essential to achieve high OER performance. It is reasonable to conclude that the $\mathrm{NH}_{3}$ treatment was essential for enhanced photocatalytic OER performance because of the nature of the photon absorber, i.e., $\mathrm{Ta}_{3} \mathrm{~N}_{5}$, for which oxidative treatment was not preferred. This study provides experimental evidence that the construction of an intimate semiconductorcatalyst interface and active catalytic sites is crucial to improve the photocatalysis.

\section{Conclusions}

This study demonstrated strategic enhancements in photocatalytic performance in an investigation of the $\mathrm{CoO}_{\mathrm{x}} / \mathrm{Ta}_{3} \mathrm{~N}_{5}$ photocatalyst system. First, nitridation after Co impregnation on $\mathrm{Ta}_{3} \mathrm{~N}_{5}$ led to drastic improvements in the photocatalytic efficiency for OER. The metallic cobalt was formed by the nitridation treatment at high temperatures, and the subsequent exposure to air likely generated a structure with metallic cobalt in the core and cobalt oxide in the shell, as indicated by STEM. This state is also consistent with the results obtained by Raman, XAS and XPS spectroscopy. However, after photocatalysis, metallic cobalt was not observed, indicating that a metallic state is not an essential component of high OER activity. Accordingly, subsequent mild oxidation led to further improvement in the photocatalytic OER, indicating that the cobalt oxide is likely a preferred active site for the OER over the metallic phase. Heat treatment at high temperatures likely facilitated the creation of intimate contact between the Co electrocatalyst and the $\mathrm{Ta}_{3} \mathrm{~N}_{5}$ photocatalyst, and subsequent mild oxidation generated a more active oxidized cobalt state without altering the chemical state of $\mathrm{Ta}_{3} \mathrm{~N}_{5}$.

\section{ASSOCIATED CONTENT}

Supporting Information. Photon distribution of the Xe lamp utilized for the photocatalytic reactions and QE measurement; theoretical XANES and EXAFS spectra; STEM, elemental mapping, and EELS spectra of $\mathrm{CoO}_{\mathrm{x}} / \mathrm{Ta}_{3} \mathrm{~N}_{5}$; photocatalytic reaction of $\mathrm{CoO}_{\mathrm{x}} / \mathrm{Ta}_{3} \mathrm{~N}_{5}$ with different time of post oxidation; photocatalytic reaction of $\mathrm{CoO}_{\mathrm{x}} / \mathrm{Ta}_{3} \mathrm{~N}_{5}$ with post oxidation using $\mathrm{Na}_{2} \mathrm{~S}_{2} \mathrm{O}_{8}$ as sacrificial reagent; STEM image of $\mathrm{CoO}_{\mathrm{x}} / \mathrm{Ta}_{3} \mathrm{~N}_{5}$ after reaction; parameter extracted from the fits of EXAFS data.

This material is available free of charge via the Internet at http://pubs.acs.org.

\section{AUTHOR INFORMATION}

\section{Corresponding Author}

* Kazuhiro Takanabe, 4700 KAUST, Thuwal, 23955-6900, Saudi Arabia, kazuhiro.takanabe@kaust.edu.sa; http://catec.kaust.edu.sa

\section{Author Contributions}


The manuscript was written through contributions of all the authors. All the authors have given approval to the final version of the manuscript.

\section{ACKNOWLEDGMENT}

This work was supported by the King Abdullah University of Science and Technology.

\section{REFERENCES}

1. Takanabe, K.; Domen, K. Toward Visible Light Response: Overall Water Splitting Using Heterogeneous Photocatalysts. Green 2011, 1, 313-322.

2. Tong, H.; Ouyang, S.; Bi, Y.; Umezawa, N; Oshikiri, M.; Ye, J. Nano-photocatalytic Materials: Possibilities and Challenges. J. Adv. Mater. 2012, 24, 229-251.

3. National Renewable Energy Laboratory (NREL) website: http://rredc.nrel.gov/solar/spectra/am1.5.

4. Maeda, K.; Domen, K. Photocatalytic Water Splitting: Recent Progress and Future Challenges. J. Phys. Chem. Lett. 2010, 1, 2655-2661.

5. Kudo, A.; Miseki, Y. Heterogeneous Photocatalyst Materials for Water Splitting. Chem. Soc. Rev. 2009, 38, 253-278.

6. Maeda, K.; Domen, K. New Non-Oxide Photocatalysts Designed for Overall Water Splitting under Visible Light. $J$. Phys. Chem. C 2007, 111, 7851-7861.

7. Abe, R. Recent Progress on Photocatalytic and Photoelectrochemical Water Splitting under Visible Light Irradiation. $J$. Photochem. Photobiol. C 2010, 11, 179-209.

8. Chen, W.J.; Ishikawa, A.; Fujisawa, H.; Takata, T.; Kondo, J.N.; Hara, M.; Kawai, M.; Matsumoto, Y.; Domen, K. Conduction and Valence Band Positions of $\mathrm{Ta}_{2} \mathrm{O}_{5}, \mathrm{TaON}$, and $\mathrm{Ta}_{3} \mathrm{~N}_{5}$ by UPS and Electrochemical Methods. J. Phys. Chem. B 2003, 107, 1798-1803.

9. Hara, M.; Hitoki, G.; Takata, T.; Kondo, J.N.; Kobayashi, H.; Domen, $\mathrm{K}$. TaON and $\mathrm{Ta}_{3} \mathrm{~N}_{5}$ as New Visible Light Driven Photocatalysts. Catal. Today 2003, 78, 555-560.

10. Hitoki, G.; Ishikawa, A.; Takata, T.; Kondo, J.N.; Hara, M.; Domen, $\mathrm{K} . \mathrm{Ta}_{3} \mathrm{~N}_{5}$ as a Novel Visible Light-Driven Photocatalyst $(\lambda<600 \mathrm{~nm})$. Chem. Lett. 2002, 7, 736-737.

11. Li, M.; Luo, W.; Cao, D.; Zhao, X.; Li, Z.; Yu, T.; Zou, Z. A Co-catalyst-Loaded $\mathrm{Ta}_{3} \mathrm{~N}_{5}$ Photoanode with a High Solar Photocurrent for Water Splitting upon Facile Removal of the Surface Layer. Angew. Chem. Int. Ed., 2013, 52, 11016-11020.

12. Li, Y.; Takata, T.; Cha, D.; Takanabe, K.; Minegishi, T.; Kubota, J.; Domen, K. Vertically Aligned $\mathrm{Ta}_{3} \mathrm{~N}_{5}$ Nanorod Arrays for Solar-Driven Photoelectrochemical Water Splitting. Adv. Mater. 2013, 25, 125-131.

13. Gao, R.; Hu, L.; Chen, M.; Wu, L. Controllable Fabrication and Photoelectrochemical Property of Multilayer Tantalum Nitride Hollow Sphere-Nanofilms. Small, 2014, 10, 15, 30383044.

14. Liu, G.; Shi, J.; Zhang, F.; Chen, Z.; Han, J.; Ding, C.; Chen, S.; Wang, Z.; Han, H.; Li, C. A Tantalum Nitride Photoanode Modified with a Hole-Storage Layer for Highly Stable Solar Water Splitting. Angew. Chem. Int. Ed. 2014, 53, 7295-7299.

15. Hara, M.; Chiba, E.; Ishikawa, A.; Takata, T.; Kondo, J.N.; Domen, K. $\mathrm{Ta}_{3} \mathrm{~N}_{5}$ and TaON Thin Films on Ta Foil: Surface Composition and Stability. J. Phys. Chem. B 2003, 107, 13441-13445.

16. Ishikawa, A.; Takata, T; Kondo, J.N.; Hara, M.; Domen, K. Electrochemical Behavior of Thin $\mathrm{Ta}_{3} \mathrm{~N}_{5}$ Semiconductor Film. J. Phys. Chem. B 2004, 108, 11049-11053.

17. Ziani, A.; Nurlaela, E.; Dhawale, D.S.; Silva, D.A.; Alarousu, E.; Mohammed, O. F.; Takanabe, K. Carrier Dynamics of A Visible-light Responsive $\mathrm{Ta}_{3} \mathrm{~N}_{5}$ Photoanode for Water Oxidation. Phys. Chem. Chem. Phys. 2015, 17, 2670-2677

18. Ma, S. S. K.; Hisatomi, T.; Maeda, K.; Moriya, Y.; Domen, $\mathrm{K}$. Enhanced Water Oxidation on $\mathrm{Ta}_{3} \mathrm{~N}_{5}$ Photocatalysts by Modification with Alkaline Metal Salts. J. Am. Chem. Soc. 2012, 134, 19993-19996.
19. Kado, Y.; Lee, C.-Y.; Lee, K.; Müller, J.; Moll, M.; Spiecker, E.; Schmuki, P. Enhanced water splitting activity of M-doped $\mathrm{Ta}_{3} \mathrm{~N}_{5}(\mathrm{M}=\mathrm{Na}, \mathrm{K}, \mathrm{Rb}, \mathrm{Cs})$ Chem. Commun. 2012, 48, 86858687.

20. Yuliati, L.; Yang, J.-H.; Wang, X.; Maeda, K.; Takata, T.; Antonietti, M.; Domen, K. Highly Active Tantalum(V) Nitride Nanoparticles Prepared from A Mesoporous Carbon Nitride Template for Photocatalytic Hydrogen Evolution under Visible Light Irradiation. J. Mater. Chem. 2010, 20, 4295 4298.

21. Fukasawa, Y.; Takanabe, K.; Shimojima, A.; Antonietti, M.; Domen, K.; Okubo, T. Synthesis of Ordered Porous Graphitic- $\mathrm{C}_{3} \mathrm{~N}_{4}$ and Regularly Arranged $\mathrm{Ta}_{3} \mathrm{~N}_{5}$ Nanoparticles by Using Self-Assembled Silica Nanospheres as a Primary Template. Chem. Asian J. 2011, 6, 103-109.

22. Liu, X.; Zhao, L.; Domen, K.; Takanabe, K. Photocatalytic Hydrogen Production Using Visible-light-responsive $\mathrm{Ta}_{3} \mathrm{~N}_{5}$ Photocatalyst Supported on Monodisperse Spherical $\mathrm{SiO}_{2}$ Particulates. Mater. Res. Bull. 2014, 49, 58-65.

23. Li, Y.; Zhang, L.; Torres-Pardo, A.; González-Calbet, J.M.; Ma, Y.; Oleynikov, P.; Terasaki, O.; Asahina, S.; Shima, M.; Cha, D.; Zhao, L.; Takanabe, K.; Kubota, J.; Domen, K. Cobalt Phosphate-modified Barium-doped Tantalum Nitride Nanorod Photoanode with 1.5\% Solar Energy Conversion Efficiency. Nature Commun. 2013, 4, 1-7.

24. Nurlaela, E.; Ould-Chikh, S.; Harb, M.; del Gobbo, S.; Aouine, M.; Puzenat, E.; Sautet, P.; Domen, K.; Basset, J-M.; Takanabe, K. Critical Role of the Semiconductor-Electrolyte Interface in Photocatalytic Performance for Water-Splitting Reactions Using $\mathrm{Ta}_{3} \mathrm{~N}_{5}$ Particles. Chem. Mater. 2014, 26, 4812-4825.

25. Zhang, J. F.; Yamakata, A.; Maeda, K.; Moriya, Y.; Takata, T.; Kubota, J.; Teshima, K.; Oishi, S.; Domen. K. CobaltModified Porous Single-Crystalline $\mathrm{LaTiO}_{2} \mathrm{~N}$ for Highly Efficient Water Oxidation under Visible Light. J. Am. Chem. Soc. 2012, 134, 8348-8351.

26. Hisatomi, T.; Maeda, K.; Takanabe, K.; Kubota, J.; Domen, $\mathrm{K}$. Aspects of Water Splitting Mechanism on $\left(\mathrm{Ga}_{1-\mathrm{x}} \mathrm{Zn}_{\mathrm{x}}\right)\left(\mathrm{N}_{1}\right.$ ${ }_{\mathrm{x}} \mathrm{O}_{\mathrm{x}}$ ) Photocatalyst Modified with $\mathrm{Rh}_{2-\mathrm{y}} \mathrm{Cr}_{\mathrm{y}} \mathrm{O}_{3}$. J. Phys. Chem. C 2009, 113, No. 51, 21458-21466.

27. Zhang, Z.; Yates Jr., J. T. Band Bending in Semiconductors: Chemical and Physical Consequences at Surfaces and Interfaces Chem. Rev. 2012, 112, 5520-5551.

28. Osterloh, F. E. Inorganic Nanostructures for Photoelectrochemical and Photocatalytic Water Splitting Chem. Soc. Rev. 2013, 42, 2294-2320.

29. Liao, M.; Feng, J.; Luo, W.; Wang, Z.; Zhang, J.; Li, Z.; Yu, T.; Zou, Z. $\mathrm{CO}_{3} \mathrm{O}_{4}$ Nanoparticles as Robust Water Oxidation Catalysts Towards Remarkably Enhanced Photostability of a $\mathrm{Ta}_{3} \mathrm{~N}_{5}$ Photoanode. Adv. Funct. Mater. 2012, 22, 3066-3074.

30. Cong, Y.; Park, H.S.; Dang, H.X.; Fan, F-R. F.; Bard, A. J.; Mullins, C.B. Tantalum Cobalt Nitride Photocatalysts for Water Oxidation under Visible Light. Chem. Mater. 2012, 24, 579-586.

31. Kasahara,A.; Nukumizu, K.; Hitoki, G.; Takata, T.; Kondo, J.N.; Hara, M.; Kobayashi, H.; Domen, K. Photoreactions on $\mathrm{LaTiO}_{2} \mathrm{~N}$ under Visible Light Irradiation. J. Phys. Chem. A 2002, 106, 6750-6753.

32. Higashi, M.; Domen, K.; Abe, R. Fabrication of an Efficient $\mathrm{BaTaO}_{2} \mathrm{~N}$ Photoanode Harvesting a Wide Range of Visible Light for Water Splitting. J. Am. Chem. Soc. 2013, 135, 10238-10241.

33. Ran, J.; Zhang, J.; Yu, J.; Jaroniecc, M.; Qiao, S. Z. Earthabundant Cocatalysts for Semiconductor Based Photocatalytic Water Splitting. Chem. Soc. Rev. 2014, 43, 7787-7812.

34. Deng, X.; Tüysüz, H. Cobalt-Oxide-Based Materials as Water Oxidation Catalyst: Recent Progress and Challenges. ACS Catal. 2014, 4, 3701-3714.

35. Yeo, B.S.; Bell, A.T. Enhanced Activity of Gold-Supported Cobalt Oxide for the Electrochemical Evolution of Oxygen. $J$. Am. Chem. Soc. 2011, 133, 5587-5593. 
36. Zhong, D.K.; Choi, S.; Gamelin, D.R. Near-Complete Suppression of Surface Recombination in Solar Photoelectrolysis by "Co-Pi" Catalyst-Modified W:BiVO ${ }_{4}$. J. Am. Chem. Soc. 2011, 133, 18370-18377.

37. Seabold, J.A.; Choi, K.-S. Effect of a Cobalt-Based Oxygen Evolution Catalyst on the Stability and the Selectivity of Photo-Oxidation Reactions of a $\mathrm{WO}_{3}$ Photoanode. Chem. Mater. 2011, 23, 1105-1112.

38. Barroso, M.; Cowan, A. J.; Pendlebury, S.R.; Gratzel, M.; Klug, D. R.; Durrant, J.R. The Role of Cobalt Phosphate in Enhancing the Photocatalytic Activity of $\alpha-\mathrm{Fe}_{2} \mathrm{O}_{3}$ toward Water Oxidation. J. Am. Chem. Soc. 2011, 133, 14868-14871.

39. Lin, F.; Boettcher, S.W. Adaptive Semiconductor/electrocatalyst Junctions in Water-splitting Photoanodes. Nat. Mater. 2014, 13, 81-86.

40. Long, M.; Cai, W.; Kisch, H. Visible Light Induced Photoelectrochemical Properties of n-BiVO ${ }_{4}$ and $n-\mathrm{BiVO}_{4} / \mathrm{p}-\mathrm{Co}_{3} \mathrm{O}_{4}$. J. Phys. Chem. C 2008, 112, 548-554.

41. Liao, L.; Zhang, Q.; Su, Z.; Zhao, Z.; Wang, Y.; Li, Y.; Lu, X.; Wei, D.; Feng, G.; Yu, Q.; Cai, X.; Zhao, J.; Ren, Z.; Fang, H.; Robles-Hernandez, F.; Baldelli, S.; Bao, J. Efficient Solar Water-splitting Using A Nanocrystalline CoO Photocatalyst. Nat. Nanotechnol. 2013, 272, 1-5.

42. Ebbinghaus, S.G.; Abicht, H.-P.; Dronskowski, R.; Müller, T.; Reller, A.; Weidenkaff, A. Perovskite-related Oxynitrides Recent developments in Synthesis, Characterisation and Investigations of Physical Properties. Prog. Solid State Chem. 2009, 37, 173-205.

43. Alhajri, N.S.; Yoshida, H.; Anjum, D.H.; Garcia-Esparza, A.T.; Kubota, J.; Domen, K. Takanabe, K. Synthesis of Tantalum Carbide and Nitride Nanoparticles using a Reactive Mesoporous Template for Electrochemical Hydrogen Evolution. J. Mater. Chem. A 2013, 1, 12606-12616.

44. Harb, M.; Sautet, P.; Nurlaela, E.; Raybaud, P.; Cavallo, L.; Domen, K.; Basset, J-M., Takanabe, K. Tuning the Properties of Visible-light-responsive Tantalum (Oxy)nitride Photocatalysts by Non-stoichiometric Compositions: A First-principle Viewpoint. Phys. Chem. Chem. Phys. 2014, 16, 20548-20560.

45. Ravel, B.; Newville, ATHENA, ARTEMIS, HEPHAESTUS: data analysis for X-ray absorption spectroscopy using IFEFFIT. J. Synchrotron Rad. 2005, 12, 537-541.

46. Joly, Y. X-ray Absorption Near-edge Structure Calculations Beyond the Muffin-tin Approximation. Phys. Rev. B 2001, 63, 125120-125129.

47. Chen, Z.; Dinh, H.N.; Miller, E. Photoelectrochemical Water Splitting Standards, Experimental Methods, and Protocols Springer New York Heidelberg Dordrecht London, 2013.

48. Hisatomi,T.; Minegishi, T.; Domen, K. Kinetic Assessment and Numerical Modeling of Photocatalytic Water Splitting toward Efficient Solar Hydrogen Production. Bull. Chem. Soc. Jpn. 2012, 85, 647655.

49. Hisatomi,T.; Maeda, K.; Takanabe, K.; Kubota, J.; Domen, K. Aspects of Water Splitting Mechanism on $\left(\mathrm{Ga}_{1-\mathrm{x}} \mathrm{Zn}_{\mathrm{x}}\right)\left(\mathrm{N}_{1-\mathrm{x}} \mathrm{O}_{\mathrm{x}}\right)$ Photocatalyst Modified with $\mathrm{Rh}_{2-\mathrm{y}} \mathrm{Cr}_{\mathrm{y}} \mathrm{O}_{3}$ Cocatalyst. J. Phys. Chem. C, 2009,113, No. 51, 21458-21466.

50. Hisatomi, T.; Takanabe, K.; Domen, K. Photocatalytic WaterSplitting Reaction from Catalytic and Kinetic Perspectives. Catal. Lett. 2015, 145, 95-108.

51. Guillermet, A.F.; Jonnson, S. Z. Metallkd. 1992, 83, 21-31.

52. Predel, B. Phase Equilibria, Crystallographic and Thermodynamic Data of Binary Alloys' of Landolt-Börnstein - Group IV Physical Chemistry, Modelung, O., Ed.; Springer-Verlag, Berlin, 1993.

53. Terao, N. Les Memoires Scientifiques de la Revue de Metallurgie 1960, 57, 96-100.
54. Clarke, J.; Jack, K.H. Chemistry and Industry, London, 1951.

55. Suzuki, K.; Kaneko, T.; Yoshida, H.; Morita, H.; Fujimori, H. Crystal structure and magnetic properties of the compound CoN. J. Alloys Comp. 1995, 224, 232-236.

56. Nurlaela, E.; Harb, M.; del Gobbo, S.; Vashishta, M.; Takanabe, K. Combined experimental and theoretical assessments of the lattice dynamics and optoelectronics of $\mathrm{TaON}$ and $\mathrm{Ta}_{3} \mathrm{~N}_{5}$. J. Solid State Chem. 2015, 229, 219-227.

57. Jiang, J.; Li, L. Synthesis of Sphere-like $\mathrm{Co}_{3} \mathrm{O}_{4}$ Nanocrystals Via A Simple Polyol Route. Mater. Lett. 2007, 61, 4894 4896.

58. Yang, J.; Liu, H.; Martens, W. N.; Frost, R.L. Synthesis and Characterization of Cobalt Hydroxide, Cobalt Oxyhydroxide, and Cobalt Oxide Nanodiscs. J. Phys. Chem. C 2010, 114, 111-119.

59. Tang, C.-W.; Wang, C.-B.; Chien, S.-H. Characterization of cobalt oxides studied by FT-IR, Raman, TPR and TG-MS Thermochimica Acta 2008, 473, 68-73.

60. Goncharov, A.F.; Crowhurst, J.; Zaug, J.M. Elastic and Vibrational Properties of Cobalt to $120 \mathrm{GPa}$. Phys. Rev. Lett. 2004, $92,1-4$.

61. de Groot, F.; Vankó, G.; Glatzel, P. The 1s X-ray Absorption Pre-edge Structures in Transition Metal Oxides. J. Phys. Condens. Matter 2009, 21,104207.

62. Cabaret, D.; Bordage, A.; Juhin, A.; Arfaoui, M.; Gaudry, E. First-principles Calculations of X-ray Absorption Spectra at the $K$-edge of $3 d$ Transition |Metals: An Electronic Structure Analysis of the Pre-edge. Phys. Chem. Chem. Phys. 2010, 12, 5619-5633.

63. Das, B.; Reddy, M. V.; Chowdari, B. V. R. X-ray Absorption Spectroscopy and Energy Storage of Ni-doped Cobalt Nitride, $\left(\mathrm{Ni}_{0.33} \mathrm{Co}_{0.67}\right) \mathrm{N}$, Prepared by a Simple Synthesis Route. $\mathrm{Na}$ noscale 2013, 5, 1961-1966.

64. Jiménez-Villacorta, F.; Espinosa, A.; Céspedes, E.; Prieto, C. Magnetic properties and short-range structure analysis of granular cobalt silicon nitride multilayers. J. Appl. Phys. 2011, 110, 113909.1-8.

65. Kühn, T.-J.; Hormes, J. ; Matoussevitch, N.; Bönnemann, H.; Glatzel, P. Site-Selective High-Resolution X-ray Absorption Spectroscopy and High-Resolution X-ray Emission Spectroscopy of Cobalt Nanoparticles. Inorg. Chem. 2014, 53, 83678375.

66. Rehr, J.J.; Albers, R.C. Theoretical Approaches to X-ray Absorption Fine Structure. Rev. Mod. Phys. 2000, 72, 621-654.

67. Longo, A.; Sciortino, L.; Giannici, F.; Martorana, A. Crossing the Boundary between Face-centred Cubic and Hexagonal Close Packed: the Structure of Nanosized Cobalt is Unraveled by A Model Accounting for Shape, Size distribution and Stacking Faults, Allowing Simulation of XRD, XANES and EXAFS. J. Appl.Cryst. 2014, 47, 1562-1568.

68. Biesinger, M.C.; Payne, B.P.; Grosvenor, A.P.; Lau, L.W.M.; Gerson, A. R.; Smart, R.St.C. Resolving Surface Chemical States in XPS Analysis of First Row Transition Metals, Oxides and Hydroxides: Cr, Mn, Fe, Co and Ni. Appl. Surf. Sci. 2011, 257, 2717-2730.

69. Seah, M.P.; Dench,W.A. Quantitative Electron Spectroscopy of Surfaces: A Standard Data Base for Electron Inelastic Mean Free Paths in Solid. Surf. Interface anal. 1979, 1, 2-11.

70. Schneider, J.; Bahnemann, D.W. Undesired Role of Sacrificial Reagents in Photocatalysis. J. Phys. Chem. Lett. 2013, 4, 3479-3483. 
1

2

3

4

5

6

7

8

9

10

11

12

13

14

15

16

17

18

19

20

21

22

23

24

25

26

27

28

29

30

31

32

33

34

35

36

37

38

39

40

41

42

43

44

45

46

47

48

49

50

51

52

53

54

55

56

57

58

59

60

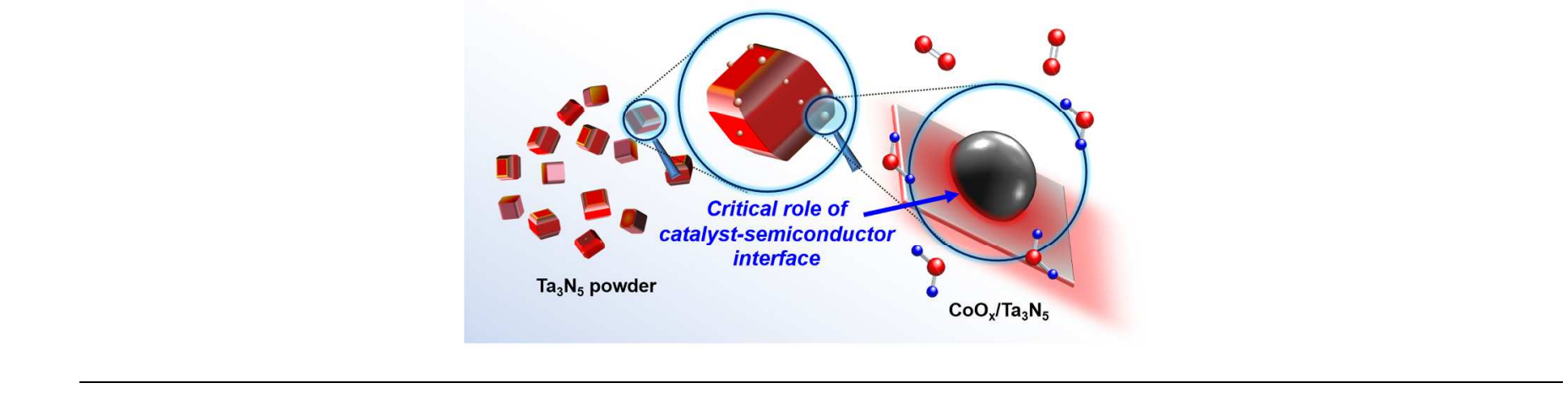 \\ Page 11 of 11}

Chemistry of Materials

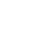

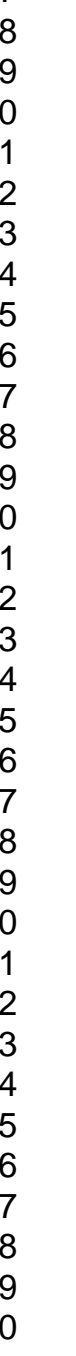

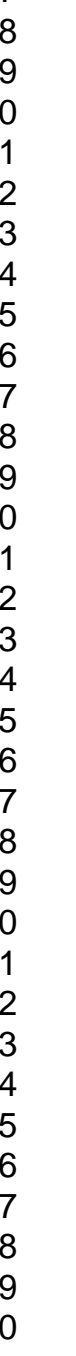

1
2
3
4
5
6
7
8
9
10
11
12
13
14
15
16
17
18
19
20
21
22
23
24
25
26

1
2
3
4
5
6
7
8
9
10
11
12
13
14
15
16
17
18
19
20
21
22
23
24
25
26

1
2
3
4
5
6
7
8
9
10
11
12
13
14
15
16
17
18
19
20
21
22
23
24
25
26

1
2
3
4
5
6
7
8
9
10
11
12
13
14
15
16
17
18
19
20
21
22
23
24
25
26

1
2
3
4
5
6
7
8
9
10
11
12
13
14
15
16
17
18
19
20
21
22
23
24
25
26

7

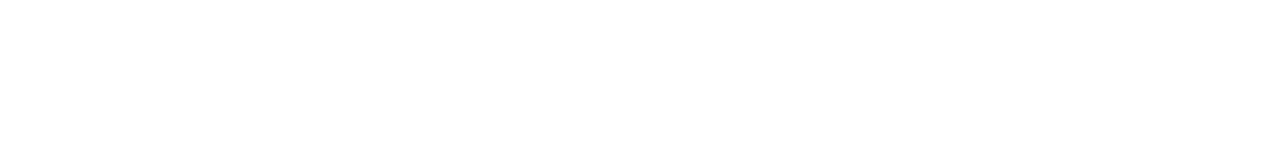

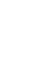

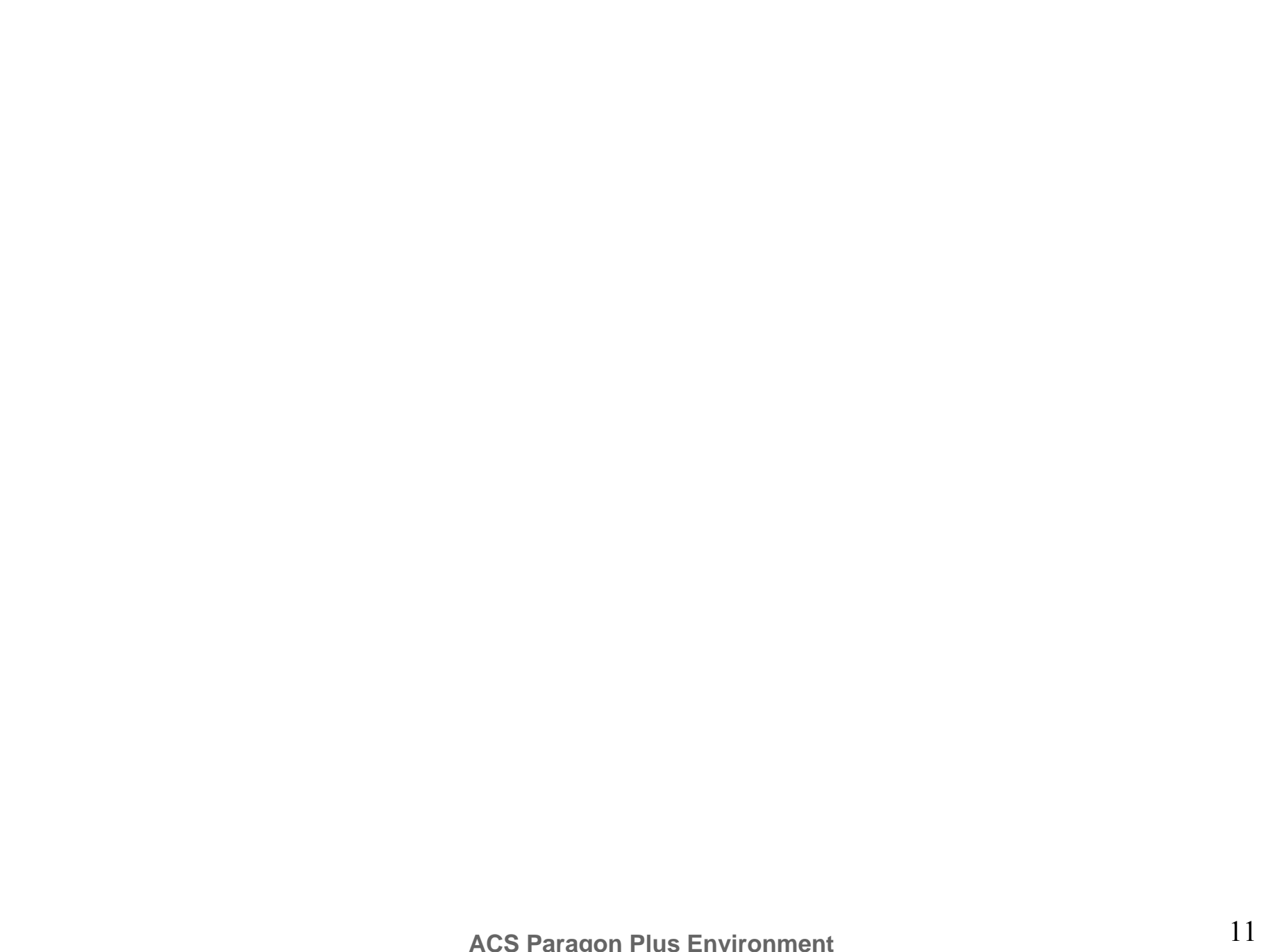

